\title{
Analysis of genetic variability in a sample of the durum wheat (Triticum durum Desf.) Spanish collection based on gliadin markers
}

\author{
Edurne Aguiriano ${ }^{1}$, Magdalena Ruiz ${ }^{1, *}$, Rosario Fité ${ }^{1}$ and Jose M. Carrillo ${ }^{2}$ \\ ${ }^{1}$ Instituto Nacional de Investigación y Tecnología Agraria y Alimentaria, Centro de Recursos Fitogenéticos, \\ Autovia de Aragón Km 36, Apdo. 1045, 28800-Alcala de Henares, Madrid, Spain; ${ }^{2}$ Escuela Técnica Superior \\ de Ingenieros Agrónomos, Dpto. Biotecnología, Ciudad Universitaria, 28040-Madrid, Spain; *Author for \\ correspondence (e-mail: mruiz@inia.es; phone: +34-91-881-92-86; fax: +34-91-881-92-87)
}

Key words: A-PAGE, Genetic variability, Germplasm, Gliadin alleles, Triticum durum

\begin{abstract}
In this work gliadin proteins were used to analyse the genetic variability in a sample of the durum wheat Spanish collection conserved at the CRF-INIA. In total 38 different alleles were identified at the loci $G l i-A 1$, Gli-A3, Gli-B5, Gli-B1, Gli-A2 and Gli-B2. All the gliadin loci were polymorphic, possessed large genetic diversity and small and large differentiation within and between varieties, respectively. The Gli-A2 and Gli$B 2$ loci were the most polymorphic, the most fixed within varieties and the most useful to distinguish among varieties. Alternatively, Gli-BI locus presented the least genetic variability out of the four main loci $G l i-A I$, $G l i-B 1, G l i-A 2$ and $G l i-B 2$. The Gli-B1 alleles coding for the gliadin $\gamma-45$, associated with good quality, had an accumulated frequency of $69.7 \%$, showing that the Spanish germplasm could be a good source for breeding quality. The Spanish landraces studied showed new gliadin alleles not catalogued so far. These new alleles might be associated with specific Spanish environment factors. The large number of new alleles identified also indicates that durum wheat Spanish germplasm is rather unique.
\end{abstract}

\section{Introduction}

Genetic diversity stored in genebanks should be carefully and comprehensively analysed to serve as an effective basis for conservation and improved access to plant genetic resources. Monitoring of intra and inter-cultivar polymorphism is essential for adequate management of accessions to maintain unchanged its genetic composition, including their heterogeneity. It will enable to preserve not only the sample as such, but also its valuable properties as multilocus combinations suitable for specific environments of the country concerned. In this context, an important goal of genebank activities is the genetic identification and registra- tion of accessions in the collections using quick, reliable and efficient analysis of polymorphic genetic markers. In wheat germplasm collections, traditional approaches are based on morphological characters which have some limitations related to small polymorphism and variation under different environmental conditions. The gliadin protein markers, as primary products of gene expression, are not affected by the plant growth environment and can reveal small changes (e.g. mutations) inaccessible to visual examinations. Gliadin alleles are inherited co-dominantly, they have revealed large levels of inter-varietal polymorphism and identification of a genotype is possible immediately by the electrophoretic 
protein phenotype. The gliadin loci control the synthesis of a group of proteins named as blocks of gliadins. The main Gli loci are located on the chromosomes of the first (Gli-l) and sixth (Gli-2) homoeologous groups (Payne et al. 1982), although other minor loci have been also found in these chromosomes (Sobko 1984; Pogna et al. 1993; Felix et al. 1996). The polymorphism of the gliadin alleles of common and durum wheat has been described previously, catalogues of the blocks have been compiled and their nomenclatures proposed (Metakovsky 1991; Kudryavtsev 1994). Gliadin electrophoresis offers advantages in evaluating wheat genetic resources in comparison to DNA molecular markers, as it is cheaper and less labour intensive to detect the polymorphism. For these reasons, several studies have analysed genetic gliadin polymorphism of wheat collections, mainly of common wheat, from different countries (Metakovsky et al. 1990, 1991, 1993, 1994, 2000; Kudryavtsev et al. 1996; Metakovsky and Branlard 1998). These studies have indicated that gliadin alleles are very efficient molecular markers to be applied in genetic analysis and to trace out genealogies of wheat cultivars.

The diversity of old varieties and forms preserved in Gene Banks is an important source of genetic variability and consequently of valuable traits for wheat improvement. In a previous work, analysis of genetic variability of common wheat landraces maintained at the CRF-INIA showed that common wheat Spanish germplasm is largely polymorphic and rather unique for gliadin alleles (Ruiz et al. 2002b). In this paper, the genetic diversity of a group of landraces and old cultivars from the durum wheat Spanish collection was characterised by gliadin polymorphism. The structure of the genetic variation was analysed and the results discussed to facilitate the use of the collection.

\section{Material and methods}

\section{Materials}

Seventeen Spanish landraces, two Spanish bred varieties ('Ledesma' and 'Lebrija'), two cultivars from Italy ('Himera' and 'Senatore Capelli'), one from Portugal ('Marques') and one from USA ('Mindum') were selected from the durum wheat collection maintained in the Plant Genetic Resources Centre (CRF-INIA) in Spain. All these materials were released before 1960 s and maintained, except 'Andalucia-344', in more than one accession at the CRF-INIA. The samples conserved in more than one entry had unknown or similar geographic origin and they were conserved by different breeders or collected in different years. A total of 51 accessions, and at least two per variety, were examined to determine the polymorphism and the structure of genetic diversity of the material.

\section{Gliadin analysis}

Gliadins were extracted from single seeds and fractionated in acid ( $\mathrm{pH}$ 3.1) polyacrylamide gel electrophoresis (A-PAGE) according to Lafiandra and Kasarda (1985). Identification of the Gli-1, Gli-2, Gli-B5 and Gli-A3 alleles in the protein spectra were performed following the catalogues and nomenclatures proposed by Kudryavtsev (1994) and Kudryavtsev et al. (1996). The Russian and Italian varieties analysed by Kudryavtsev (1994) and Kudryavtsev et al. (1996), respectively were used as test varieties for allele identification. All the results of the comparisons with the standards were reproduced at least in two runs. The new alleles found in the present work were termed as 'new-'. As a minimum of 10 grains per accession were analysed for intra-variety characterisation.

The genetic control of the alleles $b, c, e$ and $g$ at Gli-A1, $a$ and $c$ at $G l i-B 1$ and $k$ at Gli-B2 were previously analysed (Ruiz 1993; Ruiz and Carrillo 1993; Martinez 2001) in the $F_{2}$ progeny of eight crosses involving 11 Spanish landraces and old cultivars. These varieties were run with the Italian test varieties (Kudryavtsev et al. 1996) to check that the same gliadin block variants were obtained in the A-PAGE procedure used by us (Lafiandra and Kasarda 1985) and by Kudryavtsev et al. (1996).

\section{Statistical analysis}

To analyse the gliadin gene diversity within and between varieties the following genetic parameters were calculated in all populations: alleles per locus (A); effective number of alleles per locus (ne) and 
total gene diversity over populations $(\mathrm{Ht})$ divided into average gene diversity within $(\mathrm{Hs})$ and between (Dst) populations (Nei 1973). The relative magnitude of gene differentiation between populations (Gst) was estimated as Dst/Ht.

The genetic distance of Rogers (1972) as modified by Wright (1978) was used to build the UPGMA clustering phenogram, computed with the NTSYS-pc software (Rohlf 1992). The data file was made recording by a set of 0 and 1 the presence/absence of each allele.

\section{Results}

Gliadin allele composition of the varieties studied is indicated in Table 1. Altogether 34 gliadin genotypes were identified in the 23 varieties analysed (genotype 3 of 'Granja de Badajoz' and 'Recio de Baza' are identical). The two accessions of the cultivar 'Mindum' showed different gliadin phenotype, so they were studied separately and designated 'Mindum 1' and 'Mindum 2'. Fifteen varieties $(65 \%)$ were characterised by one specific type of gliadin genotype and identified as monomorphic. Eight accessions comprised two, three or four different gliadin genotypes, so they were considered polymorphic. All varieties, including the heterogeneous accessions, displayed one gliadin genotype with a frequency at least of $70 \%$ (genotype 1) which was considered the genotype of the variety. All the variety genotypes were genetically unique.

Table 2 presents the different alleles detected at the loci analysed and their frequency. A total of 38 different alleles were identified for the $G l i-A 1$, Gli-A3, Gli-B5, Gli-B1, Gli-A2 and Gli-B2 loci. For the Gli-A3 the presence or absence of allele $a$ (Figure 1: line 1) was analysed. The most polymorphic loci were Gli-A2 and Gli-B2, both with 10 alleles, though the effective number of alleles at Gli-A2 locus was 8.987 , larger than 5.192 at Gli-B2 (Table 3). The most frequent alleles at each locus were Gli-Alb (41.08\%), Gli-A3a absence (65.56), Gli-B5o (56.02), Gli-Blc (46.06\%), Gli-A2g (17.01\%) and Gli-B2h (34.02\%). The most common allele at each locus presented a frequency larger than $30 \%$, except for Gli-A2. A total of 17 new alleles, not previously catalogued (designated as ' $n e w$ ') were found at the four main loci Gli-A1, Gli-B1, Gli-A2 and Gli-B2. The blocks of the new allelic variants identified are illustrated in Figure 1. Gli-B1 and $G l i-B 2$ presented the largest number of new alleles. In general, the frequency of the new alleles was small (<8.30) except for Gli-BInew-1 (Table 2). GliAlnew-2 (characterised by the absence of any known gliadin encoded at $G(i-A 1)$, Gli-Blnew-3 and Gli-B2new-6 (Figure 1: lines 4, 3 and 16, respectively) were unique alleles, only present in one grain. Moreover, 12 alleles were rare, with a frequency below $5 \%$ (Table 2). In general, the new alleles at Gli-A2 and Gli-B2, except for Gli$B 2$ new- 6 were present in the variety genotype (genotype 1 in Table 1). Also, all new alleles at Gli-A2 were present in more than one variety. Respect to the Gli-Bl new alleles, new-4 (Figure 1: line 12) contains $\gamma-45$ gliadin, and new-1 and new-3 (Figure 1: lines 9 and 3, respectively) encoded $\gamma$-44. Neither new-2 (coding for $\gamma-43$ and 46) nor new-5 (Figure 1: lines 10 and 15, respectively) included the most typical $\gamma$-gliadins 42,44 nor 45 , in fact the allele new-5 coded for none $\gamma$-gliadin.

Statistics of genetic diversity within and between varieties are given in Table 3 . All the loci were polymorphic. The overall gene diversity in the entire sample was $\mathrm{Ht}=0.679$ with more than $95 \%$ of the diversity due to differentiation between varieties (Gst $=0.951$ ) as opposed to within varieties $(\mathrm{Hs}=0.037)$. In general, all the gliadin loci presented large genetic diversity (Ht), small genetic variation within varieties (Hs) and large inter-population differentiation (Gst). The Gli-A2, the most polymorphic locus, displayed the largest gene diversity and the less intra-variety expected heterozygosity (Hs). This locus was the most useful to distinguish between varieties (large Dst) and the most fixed within them (large Gst). In contrast, the Gli-BI showed the largest intra-population gene diversity (Hs) and the smallest genetic diversity between varieties (Gst) of the four main gliadin loci.

The dendrogram presented in Figure 2 was done with the variety genotypes (genotype 1 of each variety). The minimum genetic distance between the varieties was 0.41 . There were two clearly separated groups, G1 and G2. The G1 was formed by the cultivars 'Fanfarron' and 'Semental', both having the Gli-Bla alleles coding for $\gamma-42$ gliadin. The G2 included three varieties, 'Alaga', 'Blanquillon de Boñar' and 'Blanco de Corella', having 
Table 1. Gliadin alleles composition of 17 Spanish landraces and six old cultivars from the durum wheat Spanish collection.

\begin{tabular}{|c|c|c|c|c|c|c|c|c|}
\hline Variety & Genotype number & Genotype frequency & Gli-AI & Gli-A3 & Gli-B5 & $G \mid i-B I$ & $G l i-A 2$ & Gli-B2 \\
\hline Alaga & 1 & 1 & $b$ & - & $a$ & new-1 & $k$ & new-1 \\
\hline Almendral & 1 & 0.85 & $b$ & a & $o$ & $b$ & $f$ & $h$ \\
\hline Almendral & 2 & 0.15 & $b$ & $\mathrm{a}$ & $a$ & new-1 & $f$ & $h$ \\
\hline Andalucía 344 & 1 & 0.70 & $b$ & - & $o$ & new-5 & $g$ & $h$ \\
\hline Andalucía 344 & 2 & 0.20 & $b$ & - & $o$ & new-4 & $g$ & $h$ \\
\hline Andalucía 344 & 3 & 0.10 & $c$ & - & $o$ & new-5 & $g$ & $h$ \\
\hline Blanquillon de Boñar & 1 & 1 & $b$ & - & $a$ & new-1 & $k$ & $l$ \\
\hline Blanco de Corella & 1 & 1 & $b$ & - & $a$ & new-1 & $f$ & new-I \\
\hline Berberisco & 1 & 0.80 & $e$ & - & $o$ & $c$ & new-1 & $l$ \\
\hline Berberisco & 2 & 0.20 & $c$ & $\mathrm{a}$ & $o$ & $c$ & new-1 & $l$ \\
\hline Carita de Ratón & 1 & 1 & $e$ & - & $o$ & $c$ & new-2 & $t$ \\
\hline Fanfarrón & 1 & 1 & $g$ & a & $o$ & $a$ & $g$ & new-4 \\
\hline Forment & 1 & 1 & $b$ & $\mathrm{a}$ & $a$ & new-2 & $a$ & new-2 \\
\hline Granja de Badajoz & 1 & 0.90 & $e$ & - & $a$ & $c$ & $b$ & $t$ \\
\hline Granja de Badajoz & 2 & 0.05 & $c$ & - & $a$ & $c$ & $g$ & $h$ \\
\hline Granja de Badajoz & 3 & 0.05 & $b$ & - & $o$ & $b$ & new-3 & $h$ \\
\hline Himera & 1 & 1 & $c$ & a & $o$ & $c$ & $g$ & $t$ \\
\hline Lebrija & 1 & 0.80 & $b$ & $\mathrm{a}$ & $o$ & $b$ & $o$ & $h$ \\
\hline Lebrija & 2 & 0.10 & new-2 & - & $a$ & $c$ & $o$ & $h$ \\
\hline Lebrija & 3 & 0.05 & $b$ & - & $o$ & new-3 & $o$ & $h$ \\
\hline Lebrija & 4 & 0.05 & $b$ & $\mathrm{a}$ & $a$ & new-1 & $o$ & $h$ \\
\hline Ledesma & 1 & 1 & $c$ & - & $o$ & $c$ & $g$ & $h$ \\
\hline Marques & 1 & 0.95 & $c$ & - & $o$ & $c$ & $b$ & new-3 \\
\hline Marques & 2 & 0.05 & $c$ & $\mathrm{a}$ & $o$ & $c$ & $b$ & new-3 \\
\hline Mindum 1 & 1 & 1 & $c$ & - & $a$ & $a$ & $f$ & $h$ \\
\hline Mindum 2 & 1 & 1 & $a$ & - & $a$ & $a$ & $a$ & $a$ \\
\hline Recio de Baza & 1 & 1 & $b$ & - & $o$ & $b$ & new-3 & $h$ \\
\hline Recion & 1 & 1 & $b$ & - & $o$ & $c$ & new-1 & $t$ \\
\hline Rubio de Badajoz & 1 & 1 & $e$ & - & $a$ & $b$ & $a$ & new-5 \\
\hline Rubio de Miajadas & 1 & 1 & $b$ & $\mathrm{a}$ & $a$ & $c$ & new-4 & $h$ \\
\hline Semental & 1 & 0.95 & new-I & - & $o$ & $a$ & $b$ & $a$ \\
\hline Semental & 2 & 0.05 & new-I & - & $o$ & $a$ & $b$ & new-6 \\
\hline Senatore Capelli & 1 & 1 & $c$ & $\mathrm{a}$ & $o$ & $c$ & $o$ & $h$ \\
\hline Torcal & 1 & 1 & $e$ & - & $a$ & $c$ & new-2 & $t$ \\
\hline Verdial & 1 & 1 & $e$ & $\mathrm{a}$ & $o$ & $c$ & new-4 & $l$ \\
\hline
\end{tabular}

new-: new allele

the Gli-BInew-1 allele, the two genotypes of the foreign cultivar 'Mindum' and the landrace 'Rubio de Badajoz'. The Italian cultivars 'Himera' and 'Senatore Capelli' were grouped together and with 'Ledesma' (G3) according to the pedigree of the later
('Senatore Capelli' $\mathrm{x}$ 'Rubio de Belalcazar') and the origin of the former. The cultivars with foreign origin as 'Marques' and 'Mindum' were found to be genetically distant, showing a minimum genetic distance of 0.67 with the Spanish germplasm.

Table 2. Alleles and frequencies at each of the six gliadin loci in the 17 Spanish landraces and six old cultivars from the durum wheat Spanish collection.

\begin{tabular}{|c|c|c|c|c|c|c|c|c|c|c|c|c|c|c|c|c|c|c|}
\hline & $a$ & $b$ & $c$ & $e$ & $f$ & $g$ & $h$ & $l$ & $k$ & $o$ & $t$ & new-1 & new-2 & new-3 & new-4 & new-5 & new-6 & $?$ \\
\hline Gli-Al & 4.15 & 41.08 & 23.24 & 22.82 & & 4.15 & & & & & & 4.15 & 0.41 & & & & & \\
\hline$G l i-A 3$ & 34.44 & & & & & & & & & & & & & & & & & 65.56 \\
\hline Gli-B5 & 43.98 & & & & & & & & & 56.02 & & & & & & & & \\
\hline$G l i-B I$ & 16.60 & 14.11 & 46.06 & & & & & & & & & 14.52 & 4.15 & 0.41 & 0.83 & 3.32 & & \\
\hline Gli-A2 & 12.45 & 12.03 & & & 12.45 & 17.01 & & & 8.30 & 8.71 & & 8.30 & 8.30 & 4.15 & 8.30 & & & \\
\hline Gli-B2 & 7.88 & & & & & & 34.02 & 12.45 & & & 20.33 & 8.30 & 4.15 & 4.15 & 4.15 & 4.15 & 0.41 & \\
\hline
\end{tabular}

new-: new allele; ?: absence of allele $a$. 

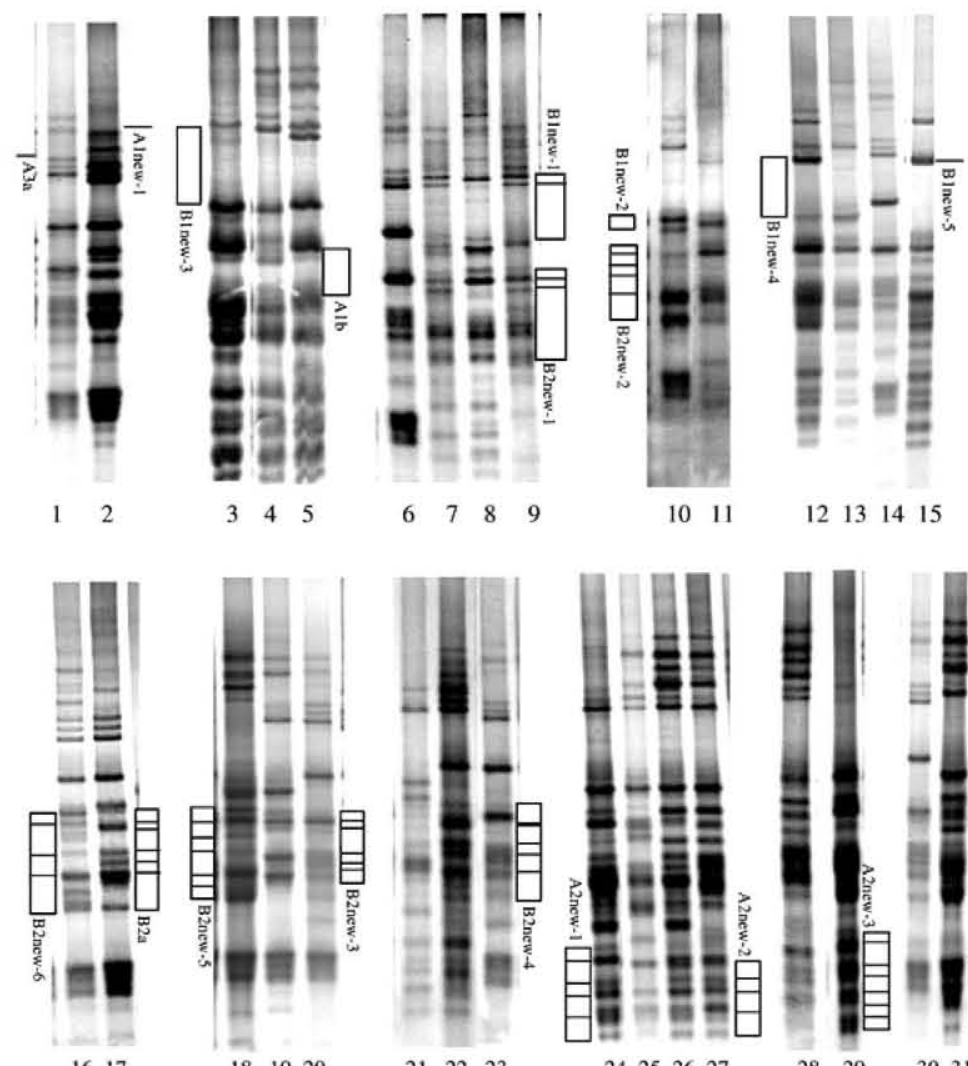

12131415

Figure 1. Gliadin electrophoretic patterns of the variety genotypes (gt.) and test varieties. Up line 1 to 15: 1) 'Langdon'; 2) 'Semental' gt. 1; 3) 'Lebrija' gt. 3; 4) 'Lebrija' gt. 2; 5) 'Lebrija' gt. 4; 6) 'Langdon'; 7) 'Alaga' gt. 1; 8) 'Simeto'; 9) 'Blanco de Corella' gt. 1; 10) 'Forment' gt. 1; 11) 'Izumrud'; 12) 'Andalucia-344' gt. 2; 13) 'Simeto'; 14) 'Langdon'; 15) 'Andalucia-344' gt. 1 . Botton line 16 to 31 : 16) 'Semental' gt. 2; 17) 'Semental' gt.1; 18) 'Rubio de Badajoz' gt. 1; 19) 'Marques' gt. 1; 20) 'Langdon'; 21) 'Trinakria'; 22) 'Fanfarron' gt. 1; 23) 'Langdon'; 24) 'Recion' gt. 1; 25) 'Krasnodarskaya' 362; 26) 'Torcal' gt. 1; 27) 'Messapia'; 28) 'Messapia'; 29) 'Recio de Baza' gt. 1; 30) 'Langdon'; 31) 'Verdial' gt. 1. Blocks controlled by corresponding new alleles identified in this work are indicated.

\section{Discussion}

In this work gliadins were used to analyse the genetic variability of Spanish durum wheat samples belonging to the collection conserved at the CRFINIA. Due to previous investigations (Ruiz 1993; Ruiz and Carrillo 1993; Kudryavtsev 1994; Kudryavtsev et al. 1996; Martinez 2001), almost all possible locations of protein components could be identified and assigned to the loci Gli-Al, Gli-A3, Gli-B5, Gli-B1, Gli-A2 and Gli-B2. The alleles detected at $G l i-A 1$ locus were allele $c$ (coding for $\omega-20-24, \gamma-51$ and one $\beta$ gliadin), $b$ (identical to $c$ but lacking the $\omega$-gliadins) and one new allele (new-1) coding only for $\omega-24$ gliadin (Figure 1: line 2). These results support the suggestion of
Kudryavtsev et al. (1996) about that it is likely that the two $\omega$-gliadins $(\omega-20-24)$ attributed to Gli-Alc are coded by other locus different from Gli-A1, but tightly linked to it. Probably, this locus is Gli-A5 mapped 2\% from Gli-Al (Metakovsky et al. 1986, 1996). Nevertheless, in the present work these $\omega$ gliadins were included in the Gli-AI protein variants until further genetic analyses are carried out. We have also detected some minor $\omega$ gliadins not included in the known blocks at Gli$A 1$ and Gli-B1. Analysis of the $F_{2}$ progeny from one inter-varietal cross indicated that these $\omega$-gliadins are not coded at Gli-B5 either (results not shown). Probably these fractions are coded at some minor loci in the chromosomes A or B in agreement with Metakovsky et al. (1996). In this 
Table 3. Gene diversity within and between durum wheat varieties for each gliadin locus and for the overall sample of 23 varieties.

\begin{tabular}{|c|c|c|c|c|c|c|}
\hline Locus & $\mathrm{A}^{\mathrm{a}}$ & $n e^{b}$ & $\mathrm{Ht}^{\mathrm{c}}$ & $\mathrm{Hs}^{\mathrm{d}}$ & $\mathrm{Dst}^{\mathrm{e}}$ & $\mathrm{Gst}^{\mathrm{f}}$ \\
\hline$G l i-A 1$ & 7 & 3.571 & 0.720 & 0.042 & 0.678 & 0.942 \\
\hline$G l i-A 3$ & 2 & 1.823 & 0.452 & 0.047 & 0.404 & 0.895 \\
\hline Gli-B5 & 2 & 1.972 & 0.493 & 0.034 & 0.459 & 0.931 \\
\hline Gli-BI & 8 & 3.526 & 0.716 & 0.054 & 0.663 & 0.925 \\
\hline$G l i-A 2$ & 10 & 8.987 & 0.889 & 0.008 & 0.881 & 0.992 \\
\hline Gli-B2 & 10 & 5.192 & 0.807 & 0.015 & 0.792 & 0.981 \\
\hline Mean & 6.500 & 4.178 & 0.679 & 0.033 & 0.646 & 0.951 \\
\hline
\end{tabular}

${ }^{\text {a Alleles per locus. }}$

${ }^{\mathrm{b}}$ Effective number of alleles per locus.

'Total gene diversity.

${ }^{\mathrm{d}}$ Average gene diversity within varieties.

eAverage gene diversity between varieties.

${ }^{\mathrm{f}}$ Relative magnitude of gene differentiation between varieties.

work, all the gliadin loci analysed were polymorphic, possessed large genetic diversity and small and large differentiation within and between varieties, respectively (Table 3 ). The Gli-A2 and Gli-B2 loci were the most polymorphic, the most fixed within varieties and the most useful to distinguish between varieties (Tables 2 and 3). Similar results were obtained by Kudryavtsev et al. (1996) in modern Italian durum wheat cultivars and by Ruiz et al. (2002b) in a group of Spanish bread wheat landraces. In these studies the loci of the sixth homeologous group showed the greatest variability and Gli-A2 alleles were the most equally distributed. Alternatively, Gli-B1 locus presented the least genetic variability out of the four main loci Gli-A1, Gli-B1, Gli-A2 and Gli-B2 (Table 3). By the way, Gli-Bl was the most useful and one of the most polymorphic loci in discriminating Spanish common wheat varieties (Ruiz et al. 2002a). These contrasting results between common and durum wheat could be due to the genetic relationship of Gli-BI with quality in durum wheat. It is known that alleles at $G l i-B I$ code for the gliadins $\gamma-42$ and $\gamma-45$ used as genetic markers of gluten quality (Damidaux et al. 1978). In this work, the alleles including the $\gamma-45$, associated with good quality, had an accumulated frequency of $69.7 \%$, showing that this gliadin was the most common in the Spanish germplasm. On the other hand, the GliBIa $(16.60 \%)$ was the only allele coding for the $\gamma-42$, associated with poor gluten quality. We can deduce that durum wheat Spanish germplasm is a good source of protein allelic variants for breeding quality and to improve the genetic background of modern cultivars. In fact, the frequencies of $G l i-B 1$ alleles containing $\gamma-45$ and $\gamma-42$ were $58 \%$ and $36 \%$, respectively, in the bred varieties grown in Spain in the 80s (Carrillo et al. 1990) and 77\% and $19 \%$, respectively, in the bred varieties grown in the 90 s (Nieto-Taladriz et al. 1997). The increase of frequency of Gli-BI alleles coding for $\gamma-42$ in modern bred varieties, especially in the $80 \mathrm{~s}$, respect to landraces could be due to the introduction of foreign germplasm, mostly from CIMMYT, in the Breeding Programs. However, the comparisons of data of the $80 \mathrm{~s}$ and $90 \mathrm{~s}$ indicate that a selection pressure towards good gluten quality has been taken place for the last 10 years. The new Gli-BI alleles, new- 1 and new-3 coding for $\gamma-44$ (14.93\%) and present in the Spanish landraces, have not been detected in any modern cultivars grown in Spain (Carrillo et al. 1990; Nieto-Taladriz et al. 1997). The genetic control of allele new-l from the Spanish landrace 'Alaga' was studied in an earlier research (Ruiz and Carrillo 1993). Kudryavtsev et al. (1996) pointed out that this allele, also present in cultivar 'Lambro', was probably inherited from Triticum turgidum L. ssp. dicoccoides (Körn. ex Asch. et Graebn.) Thell. or Triticum carthlicum (Nevski) Mackey. Asins and Carbonell (1989) also detected isoenzymatic characteristics of Triticum dicoccoides in durum wheat germplasm from North Africa. This information could be useful to select material from the collection for breeding purposes because other interesting genes from Triticum turgidum ssp. dicoccoides could be also inherited and be present in these genotypes.

All the Spanish landraces analysed showed new alleles in contrast to the foreign cultivars as 'Himera', 'Mindum' and 'Senatore Capelli'. 


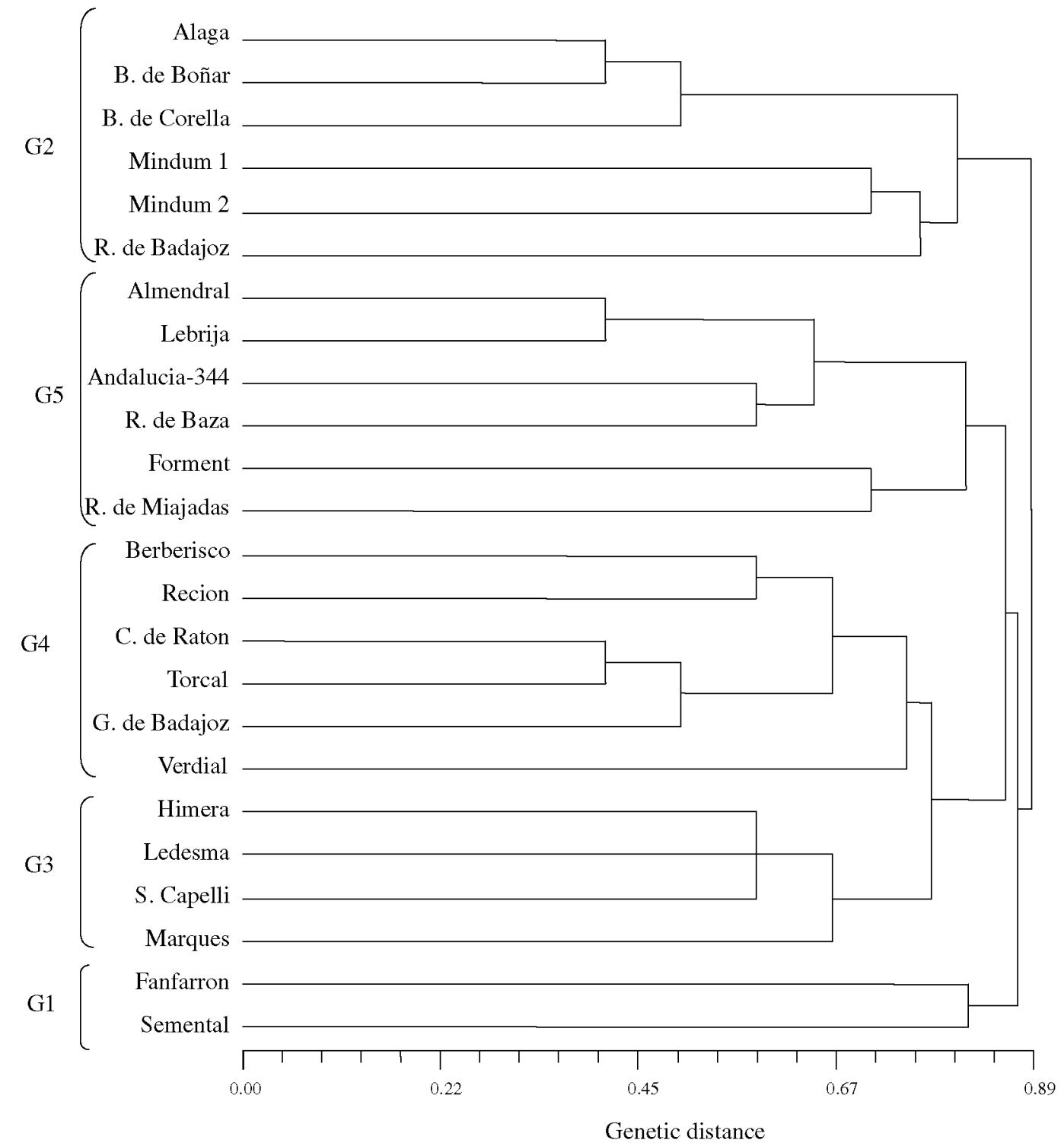

Figure 2. Dendrogram of the 17 Spanish landraces and six old cultivars from the durum wheat Spanish collection based on their dissimilarity in gliadin genotype.

'Marques', coming from Portugal, carried the Gli$B 2 n e w-3$, a new allele not found in the Spanish material. The genotype of the variety 'Granja de Badajoz', 'Lebrija' and 'Ledesma' possessed none new alleles, too. The former is a bred variety selected from a Spanish landrace and 'Lebrija' and 'Ledesma' are bred varieties from crosses of landraces with 'Senatore Capelli'. These results indicate that the new alleles detected in this work could be regarded as specific to Spanish landraces, being Gli-BI and Gli-B2 the loci with the largest number of new alleles identified. The Gli-Blnew-1, Gli-B2new-1 and all the new alleles at Gli-A2 were observed in more than one Spanish variety genotype. The Gli-BInew- 1 and Gli-B2new- 1 were only present in landraces from the North of Spain while the Gli-A2 new alleles occurred in landraces from the South of the country (most of them clustered in G4 of Figure 2). It is known that landraces posses large level of adaptation to the particular environment of their cultivation. Moreover, gliadin genes, not subjected to direct selection by breeders, 
could be linked to genes directly selected under different environmental conditions. So, these new gliadin alleles might be associated with specific Spanish environment factors. The large number of new alleles, 17 in contrast to six found in other studies (Metakovsky et al. 1994; Metakovsky and Branlard 1998), also indicates that durum wheat Spanish germplasm is rather unique. This variability is conserved nowadays because Spanish breeders and curators did an important effort to collect and maintain this germplasm in ex-situ collections before being affected by the genetic erosion in the field. The same conclusion with regard to Spanish common wheat germplasm was found in a previous research (Ruiz et al. 2002b). The knowledge about the distribution of alleles, especially of rare alleles, is important to estimate the amount of gene variability but also to the creation of core collections because the core entries should contain as many alleles as possible.

Very few reports have studied the gliadin polymorphism in durum wheat cultivars (Kudryavtsev 1994; Kudryavtsev et al. 1996), so the comparisons between germplasm from different countries are very limited. Kudryavtsev et al. (1996) analysed the gliadin polymorphism of 72 modern Italian durum wheat cultivars. In that work a total of 27 alleles were identified at the loci Gli-Al, Gli-B5, $G l i-B 1, G l i-A 2$ and $G l i-B 2$ in contrast to the 38 found in the 23 varieties analysed in this work. The total gene diversity was also larger in the Spanish germplasm (0.679 vs. 0.528). The comparative analyses of the dendrograms obtained in both researches indicate that Italian material is more related than the Spanish one. This result is according to Asins and Carbonell (1989) who also found small variability in Italian entries maintained in the Consiglio Nazionale delle Ricerche (CNR) in Bari. It was observed that $G l i-A 1 b$, very typical in the Spanish germplasm was not present in the Italian one. Alternatively, allele $c$, the most frequent in Italian cultivars, only occurred in three Spanish local varieties ('Andalucia-344', 'Berberisco' and 'Granja de Bandajoz') and not in the most common genotype. This allele was also found in the cultivars 'Himera', 'Ledesma', 'Marques', 'Mindum' and 'Senatore Capelli', all of them of foreign origin or having 'Senatore Capelli' in its pedigree as 'Ledesma'. The two alleles at Gli-B5 showed similar frequencies in the Spanish material while in Italian germplasm allele $o$ was more widespread. Allele Gli-B5a was observed together with the alleles Gli-Bla, $b$ and $c$, but in Spanish germplasm Gli-Bla-Gli-B5a did not appear as frequently linked as in the Italian material. For $G l i-B 1$, allele $c$ was the most frequent in both researches, probably by its genetic relationship with good gluten quality (Damidaux et al. 1978). Allele Gli-A2o was the most common in Italian germplasm whereas it was absent in Spanish landraces. Kudryavtsev et al. (1996) speculated that this allele comes from North Africa and it was introduced in the Italian cultivars through cultivar 'Capelli'. In the present work only 'Senatore Capelli' and 'Lebrija' had this allele. This result corroborates the suggestion made by Kudryavtsev et al. (1996) because 'Lebrija' has 'Senatore Capelli' in its pedigree. For $G l i-B 2$, allele $h$ was the most frequent in both studies while alleles $l$ and $t$ were also widely distributed in Spanish germplasm. All the Spanish landraces carrying the alleles Gli-BlC (Figure 2, G4 plus 'Rubio de Miajadas') and Gli-B2h (Figure 2, G5 except Forment), the most frequent at these loci (Table 1), come from the South of Spain. These alleles were also present in the cultivar 'Senatore Capelli' which has North African origin. It is plausible that these alleles could have reached Spain from North Africa. Asins and Carbonell (1989) suggested that the Mediterranean would be a secondary centre of durum wheat diversity involving the countries Egypt, Yugoslavia, Tunisia, France, Spain and Greece, being Egypt a microcenter of genetic diversity. The large differences between the Spanish and Italian materials in most frequent alleles, mainly for the Gli-AI and Gli-A2 loci, support that these gliadin alleles may possess some adapted value, at least as markers of linked genes influencing wheat adaptation. In the case of the Italian cultivars these alleles could be come from some specific parents used intensively in the breeding programs (Kudryavtsev et al. 1996).

Gliadin alleles have revealed to be a powerful tool to estimate the amount and nature of gene diversity and to corroborate known historical relationships between varieties. Genetic analyses have indicated that the durum wheat Spanish collection maintained at the CRF is largely structured genetically with about $95 \%$ of the total genetic diversity occurring between accessions. The old varieties analysed are rather unique and posses a large genetic variability. 
The results obtained in the present work suppose a valuable aid to create the durum wheat core collection and facilitate the selection of materials for quality breeding and development of improved adaptable cultivars.

\section{Acknowledgements}

We thank Dr Kudryavtsev for his recommendations, and Dr Boggini and Vavilov Genebank from Russia for providing the samples of the Italian and Russian test varieties, respectively. This work was supported by the grant RF-01-021 from the INIA of Spain and the AGL 2003-6382 from Comision Interministerial de Ciencia y Tecnología (CICYT) of Spain. E. Aguiriano receives a pre-doctoral scholarship from the INIA.

\section{References}

Asins M.J. and Carbonell E.A. 1989. Distribution of genetic variability in a durum wheat world collection. Theor. Appl. Genet. 77: 287-294.

Carrillo J.M., Vázquez J.F. and Orellana J. 1990. Relationship between gluten strength and glutenin proteins in durum wheat cultivars. Plant Breed. 104: 325-333.

Damidaux T., Autran J.C., Grignac L. and Feillet P. 1978. Mise en évidence de relations applicables en sélection entre l'électrophorégramme des gliadins et les propriétés viscoélastiques du gluten de Triticum durum Desf. C.R. Acad. Sci. Ser. D 287: 701-704.

Felix I., Martinant J.P., Bernard M., Bernard S. and Branlard G. 1996. Genetic characterization of storage proteins in a set of $F_{1}$-derived haploid lines in bread wheat. Theor. Appl. Genet. 92: 340-346.

Kudryavtsev A.M. 1994. Genetics of gliadin of spring durum wheat (Triticum durum Desf.). Russian J. Genet. 30: 69-75.

Kudryavtsev A.M, Boggini G., Benedettelli S. and Illichevskii N.N. 1996. Gliadin polymorphism and genetic diversity of modern Italian durum wheat. J. Genet. Breed. 50: 239-248.

Lafiandra D. and Kasarda D.D. 1985. One and two-dimensional (two-pH) polyacrylamide gel electrophoresis in a single gel: separation of wheat proteins. Cereal Chem. 62: 314-319.

Martinez M.C. 2001. Prolamins in durum wheat: inheritance and relation with pasta quality parameters. Ph.D. Thesis. Universidad Politécnica, ETS. Ingenieros Agrónomos, Madrid.

Metakovsky E.V. 1991. Gliadin allele identification in common wheat. 2. Catalogue of gliadin alleles in common wheat. J. Genet. Breed. 45: 325-344.

Metakovsky E.V. and Branlard G. 1998. Genetic diversity of French common wheat germplasm studied using gliadin alleles. Theor. Appl. Genet. 96(2): 209-218.
Metakovsky E.V., Akhmedov M.G. and Sozinov A.A. 1986. The genetic analysis of gliadin-encoding genes reveals clusters and remote genes. Theor. Appl. Genet. 73: 278-285.

Metakovsky E.V., Knezevic D. and Javornik B. 1991. Gliadin allele composition of Yugoslav winter wheat cultivars. Euphytica 54: 285-295.

Metakovsky E.V., Gomez M., Vazquez J.F. and Carrillo J.M. 2000. Large genetic diversity of Spanish common wheat as judged from gliadin alleles. Plant Breed. 119: 37-42.

Metakovsky E.V., Pogna N.E., Biancardi A.M. and Redaelli R. 1994. Gliadin allele composition of common wheat cultivars grown in Italy. J. Genet. Breed. 48: 55-66.

Metakovsky E.V., Wrigley C.W., Bekes F. and Gupta R.B. 1990. Gluten polypeptides as useful genetic markers of dough quality in Australian wheats. Aust. J. Agric. Res. 41: 289-306.

Metakovsky E.V., Ng P.K.W., Chernakov V.M., Pogna N.E. and Bushuk W. 1993. Gliadin alleles in Canadian western red strong wheat cultivars: use of two different procedures of acid polyacrylamide gel electrophoresis for gliadin separation. Genome 36: 743-749.

Metakovsky E.V., Chernakov V.M., Upelniek V.P., Redaelli R., Dardevet M., Branlard G. and Pogna N.E. 1996. Recombination mapping of minor $\omega$-gliadin -coding loci on chromosome 1A of common wheat: a revision. J. Genet. Breed. 50: 277-286.

Nei M. 1973. Analysis of gene diversity in subdivided populations. Proc. Natl. Acad. Sci. USA 70: 3321-3323.

Nieto-Taladriz M.T., Ruiz M., Martinez M.C., Vazquez J.F. and Carrillo J.M. 1997. Variation and classification of B lowmolecular-weight glutenin subunit alleles in durum wheat. Theor. Appl. Genet. 95: 1155-1160.

Payne P.I., Holt L.M., Lawrence C.J. and Law C.N. 1982. The genetics of gliadin and glutenin the major storage proteins of the wheat endosperm. Qualit. Plant Foods Hum. Nutr. 31: 229-241.

Pogna E.N., Metakovsky E.V., Redaelli R., Raineri F. and Dachkevitch T. 1993. Recombination mapping of Gli-5, a new gliadin-coding locus on chromosomes $1 \mathrm{~A}$ an $1 \mathrm{~B}$ in common wheat. Theor. Appl. Genet. 87: 113-121.

Rogers J.S. 1972. Measures of genetic similarity and genetic distance. In: Studies in Genetics VII. University of Texas, Austin, TX, pp. 145-153.

Rohlf F.J. 1992. NTSYS-pc Numerical Taxonomy and Multivariate Analysis System. Exeter software, New York.

Ruiz M. 1993. Genetic analysis of the gluten proteins and their relation with quality in durum wheat (Triticum turgidum L.). Ph.D. Thesis, Universidad Politécnica, ETS. Ingenieros Agrónomos, Madrid.

Ruiz M. and Carrillo J.M. 1993. Linkage relationships between prolamin genes on chromosomes $1 \mathrm{~A}$ and $1 \mathrm{~B}$ in durum wheat. Theor. Appl. Genet. 87: 353-360.

Ruiz M., Metakovsky E.V., Rodriguez-Quijano M., Vazquez J.F. and Carrillo J.M. 2002a. Assessment of storage protein variation in relation to some morphological characters in a sample of Spanish landraces of common wheat (Triticum aestivum L. ssp. vulgare). Genet. Resour. our. Crop Evol. 49: 371-382.

Ruiz M., Rodriguez-Quijano M., Metakovsky E.V., Vazquez F. and Carrillo J.M. 2002b. Polymorphism, variation and genetic identity of Spanish common wheat germplasm based on gliadin alleles. Field Crops Res. 79: 185-196. 
Sobko T.I. 1984. Identification of a new locus which controls the synthesis of alcohol-soluble endosperm proteins in soft winter wheat. J. Agric. Sci. Kiev 7: 78-80 (in Russian).
Wright S. 1978. Evolution and the Genetics of Populations, vol. 4. Variability within and Among Natural Populations. University of Chicago Press, Chicago. 